\title{
Un adieu à la politique et à la FMH
}

\section{Bruno Henggi}

Responsable Affaires publiques, FMH

Au début de l'année dernière, le conseiller aux Etats Joachim Eder a décidé de ne pas se représenter aux élections fédérales d'automne 2019. Au printemps de cette année, il a aussi cessé son activité de consultant pour la FMH. Pour la FMH, ce politicien PLR zougois aura été un consultant et un partenaire très précieux durant deux législatures. Il a œuvré avec une grande compétence et beaucoup d'intégrité pour le corps médical.

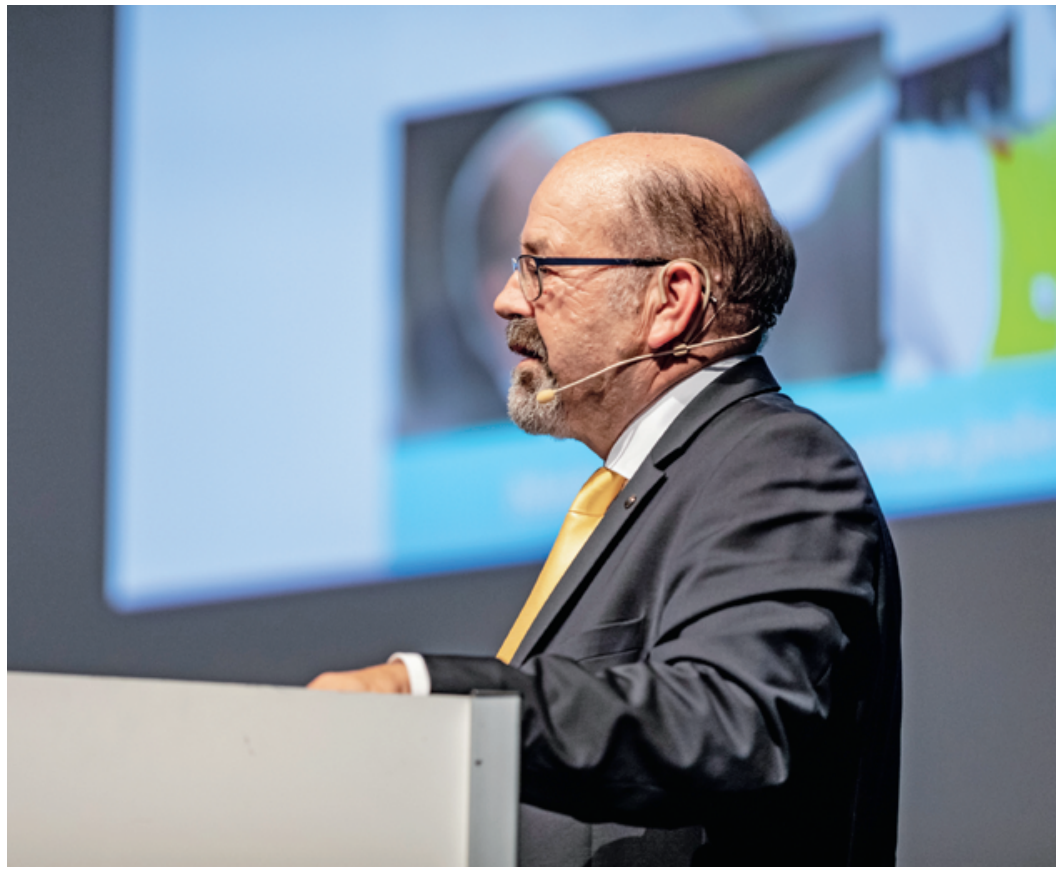

Le conseiller aux Etats Joachim Eder

\section{Consultant pour la FMH}

Pour la FMH, Joachim Eder est devenu un interlocuteur et un partenaire essentiel grâce à ses vastes connaissances en politique de santé, son large réseau, sa grande influence politique et sa faculté à trouver des solutions au-delà des partis et groupes politiques. La FMH s'est assuré sa collaboration et l'a engagé comme consultant dans son sounding board entre 2013 et 2020, jusqu'à son retrait de la vie politique. Une collaboration d'autant plus précieuse lorsque Joachim Eder est entré à la commission de la santé en 2015.

Politicien de milice consciencieux, Joachim Eder prenait toujours soin de recueillir les avis et points de vue les plus divers. En tant que président du conseil d'administration de 3R, il s'est ainsi engagé pour la recherche de méthodes alternatives à l'expérimentation animale - une volonté portée aussi bien par la protection des animaux que par l'industrie pharmaceutique. Il a été membre du conseil de fondation d'une assurance-maladie, a présidé la fondation Promotion Santé Suisse et s'est engagé, en tant que coprésident, dans tous les groupes parlementaires traitant de questions en lien avec la politique de santé.

Joachim Eder a consacré une grande partie de sa carrière professionnelle à la chose publique. En 1983, alors âgé de 32 ans et enseignant secondaire, il est élu au Grand Conseil du canton de Zoug pour le PLR. En 2001, il survit au terrible attentat au Parlement de Zoug, avant d'entrer au Conseil d'Etat cantonal où il sera pendant onze ans (jusqu'en 2012) à la tête de la Direction de la santé. Enfin, lors des élections fédérales de 2011, il se hisse sur la scène politique nationale pour représenter son canton au Conseil des Etats.

\section{Appel à l'action}

Dans son discours passionné devant la Chambre médicale en octobre 2019, Joachim Eder n’a pas hésité à re-

Il s'est ainsi engagé pour la recherche de méthodes alternatives à l'expérimentation animale.

mettre en question certains principes fondamentaux partagés par les représentants de la faîtière des méde- 
cins. Contrairement à l'image d'une profession isolée et mal aimée véhiculée à l'interne, la FMH devrait selon lui utiliser sa bonne position pour défendre ses intérêts. Son image auprès de la population est bonne et sa compétence en tant qu'acteur de la santé est reconnue. Il faut profiter de cette situation confortable, a-t-il souligné. La FMH devrait utiliser sa force pour

Dans son discours passionné, il n'a pas hésité à remettre en question certains principes fondamentaux partagés par les représentants de la faîtière des médecins.

nouer de nouveaux contacts et entretenir des alliances durables. Cela lui permettrait de renforcer sa présence politique tout en facilitant la prise de décision au Parlement, ce qui serait aussi très apprécié des milieux politiques. On attend également de la FMH qu'elle communique de manière plus offensive, notamment avec des messages et des prises de position positives. Si la FMH est arrivée ces derniers temps à se défaire de son ancienne image de "Nein-Sager», les milieux politiques ont cependant encore l'impression que les aspects purement financiers sont trop souvent mis en avant, au détriment des patients.

\section{Nouer des alliances et défendre une politique constructive}

Mais le conseiller aux Etats en a aussi profité pour louer les mérites de la Chambre médicale. Pour lui, une date illustre parfaitement toute l'efficacité d'un dialogue constructif: le 12 juillet 2019, lorsque les partenaires tarifaires FMH et curafutura ont remis le nouveau tarif ambulatoire TARDOC au Conseil fédéral, après plus de trois ans et demi de travaux, en vue d'une entrée en vigueur au $1^{\text {er }}$ janvier 2021. Un événement dont Joachim Eder a pris connaissance avec une grande satis- faction. Il a donc profité de son discours devant la Chambre médicale pour féliciter l'ensemble du corps médical pour cette grande réussite, rendue possible grâce au dévouement et à l'énergie déployée par de nombreux membres.

\section{Parler d'une seule voix}

Durant sa carrière, Joachim Eder a été un politicien proche du peuple, doué d'un esprit civique, intéressé, intègre et honnête. Très humain, aussi. Il avait une façon très sympathique d'exprimer son désir, en tant que politicien, de nouer des relations d'amitié. Parler d'une seule voix est essentiel en politique, a-t-il expliqué avec enthousiasme à la Chambre médicale. Pour illustrer son propos, il n’a pas hésité à rappeler les délibérations concernant la loi sur les produits du tabac à la commission de la santé du Conseil des Etats en août

\section{Il avait une façon très sympathique d'exprimer} son désir, en tant que politicien, de nouer des relations d'amitié.

2019. Le ministre des Affaires étrangères, Ignazio Cassis, s'était retrouvé sous le feu des critiques après avoir envisagé un partenariat de sponsoring avec un cigarettier pour le pavillon suisse de l'Expo 2020 de Dubaï. Cela avait provoqué un petit tremblement de terre au sein de la commission de la santé qui avait alors décidé, sous la direction active de son président Joachim Eder, de créer les conditions propices à une ratification de la Convention-cadre de l'OMS pour la lutte antitabac. Ce que Joachim Eder a omis de préciser, en revanche, est connu de tous: il aurait été grandement félicité pour le signal politique clair lancé par la commission du Conseil des Etats sous sa présidence. Et ça aussi, c'est un facteur de succès dans la défense des intérêts politiques: l'éloge est un outil de conduite efficace. 